\title{
Sustainability regulations in urban planning: the experience of the Autonomous Community of Valencia (Spain)
}

\author{
J. L. Miralles i Garcia \\ Department of Urban and Regional Planning, \\ Polytechnic University of Valencia, Spain
}

\begin{abstract}
Changes in land use have been very intense in Spain over recent years, these being especially important in the Autonomous Community of Valencia (ACV). Changes in the situation of economic activities and in the real estate market have also taken place in a drastic way in a very short time. Artificial surfaces in the ACV increased 1.770 ha per year from 2000 to 2006 on and the increase between 1990 and 2000 was 1.794 ha per year. Between 2004 and 2007, an intense process of regulation, both of urban and regional planning, took place; three Acts and two Regulations were introduced by the ACV and another two Regulations were introduced by Central Government. Experience has been very irregular up until today. Laws have introduced many new concepts and ideas, but in many cases, the way in which have been designed and developed has rarely been systematic or coherent. Despite all of these legal changes, a complete set of essential problems already exists that has yet been not approached.
\end{abstract}

Keywords: urban planning, landscape architecture, landscape ecology, landscape management, sustainability, public participation.

\section{Introduction}

Changes in land use have been very intense in Spain over recent years, these being especially important in the Autonomous Community of Valencia (ACV). Changes in the situation of economic activities and in the real estate market have also taken place in a drastic way in a very short time.

In the Second Conference on Sustainable Development and Planning, which took place in Algarve (Portugal) in June 2007, our contribution exposed how the 
ACV was editing a group of laws in order to introduce sustainability and life quality criteria both in land and urban planning. In addition, specific regulations on landscape planning were introduced and, at the same time, Central Government regulated the introduction of Strategic Environmental Assessment (SEA) on land planning processes all over the country.

Two years have gone by, and so it is possible to make a first evaluation of this experience. However, it must also be said that world changes during this period have also been very intense. For this reason the situation initially designed to implement these laws has changed considerably.

The situation of the real estate market has completely changed both in Spain and particularly in the ACV and, in the last two years, the market has changed from a situation of "boom" to quasi stagnation. In this paper we analyze the real experience that has taken place in this confusing period.

Between 2004 and 2007, an intense process of regulation, both of urban and regional planning, took place [1, 2]: three Acts and two Regulations were introduced by the ACV and another two Regulations were introduced by Central Government.

Let us recall matters taken into consideration by ACV regulations:

1. Guidelines concerning sustainability

1. Rational land use

2. Efficient use of water resources and protection of its quality

3. Protection of natural media

4. Conservation and valuation of cultural heritage

5. Revitalization of rural heritage

6. Prevention of natural or induced risks

7. Coastal arrangement

2. Guidelines concerning citizens' quality of life

1. Improvement of urban environments

2. Public transport

3. Public facilities

4. Housing access

3. Guidelines concerning land planning

1. Fixing of substantive items for urban arrangements in the Plan

4. Guidelines concerning landscape

1. Contents in the urban plan for landscape protection, management and planning according to the European Landscape Convention of Florence 2000

2. Procedures for public participation in landscape valuation

At the same time Central Government has passed three Acts in order to incorporate implementation of European Directives: the Aarhus Convention on Access to information, public participation in decision-making and Access to justice in environmental matters (Act 27/2006, 27 $7^{\text {th }}$ July); the Strategic Environmental Assessment (SEA) (Act 9/2006, 28 ${ }^{\text {th }}$ April); and the sustainable development principle in land regulation, land planning, land activity, land transformation and land use (Act 8/2007, $28^{\text {th }}$ May and Act 2/2008, $20^{\text {th }}$ June). 
These new laws have as an objective the establishment of the basis for sustainable development. However, they are a too wide a group of regulations, sometimes complex, sometimes incoherent, and even contradictory. It is difficult for professionals, and even by judges, to thoroughly understand the group of regulations.

On the other hand, so called "land developers" in the ACV have been able to develop private land since 1994 and in Spain since the approval of Law 8/2007. This "land developer" works on delegation by administration (generally local administration) to urbanize land. The "land developer" finances works and obtains payment by landowners who get back their soil urbanized and prepared to be built. Part of the resulting lots pertains to the land owners, and part to the administration, who acquires a share of $10 \%$ free of any payment.

The European Commission differs on the character of these contracts (public contracts as by the EC, and of a special character as by Valencia's Government). The Land Act of ACV of Valencia (Law 16/2005, 30 ${ }^{\text {th }}$ December) is resorted to in the Strasbourg Tribunal.

In addition, European Parliament has passed several advisories against macroprojects that have been developed in the ACV during the real state "boom".

For this reason further changes to the laws are probable.

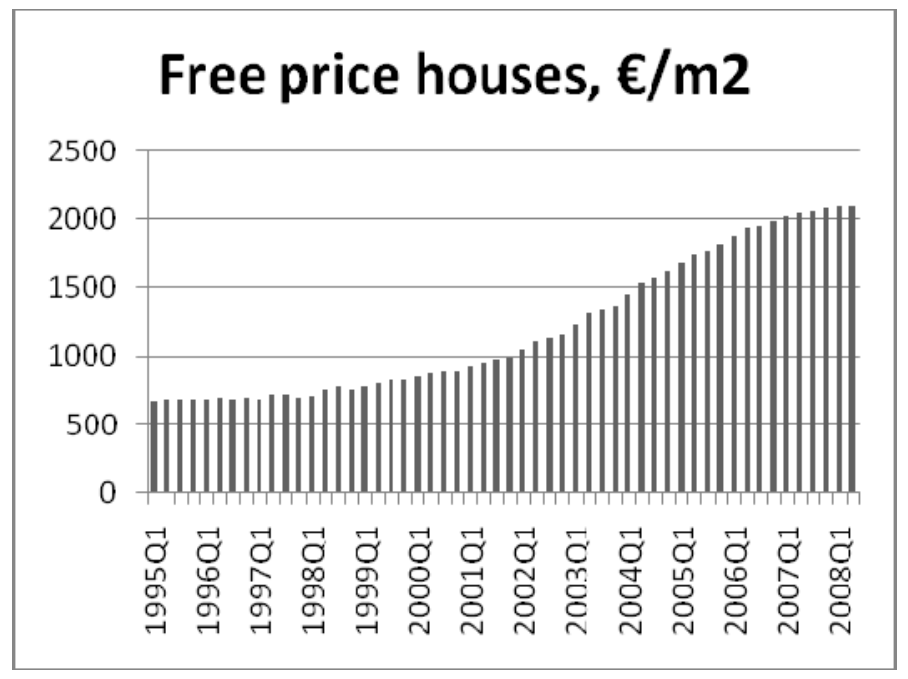

Figure 1: $\quad$ Free price houses evolution $(€ / \mathrm{m} 2)$. Source: Ministerio de la Vivienda.

\section{The change of cycle in the real estate market}

Changes in the economic cycle have had a direct influence on this situation. In Fig. 1 the evolution of the "average price" of free housing in Spain is shown. It can be observed how the average price has grown from $800 € / \mathrm{m} 2$ in 1997 , up to 
$2.000 € / \mathrm{m} 2$ in 2007 . This figure has a direct relation with the so called "real estate boom" period.

This evolution of prices is accompanied by a continuous increase in the amount of housing being built. In Table 1, we can observe a continuous increase in permits until 2006. We can consider 2006 as the year in which the crisis started. By 2007 the number of permits had decreased.

Table 1: Visas for construction works: housing number. Source: DG Programación Económica. Ministerio de Fomento.

\begin{tabular}{|c|c|c|c|c|c|c|}
\hline Year & Alicante & Castellón & Valencia & C. Valenciana & Spain & $\begin{array}{c}\% \text { CV / } \\
\text { AND }\end{array}$ \\
\hline 2000 & 44.447 & 12.223 & 31.234 & 87.904 & 594.820 & 14,8 \\
\hline 2001 & 40.954 & 11.401 & 27.067 & 79.422 & 561.186 & 14,2 \\
\hline 2002 & 44.426 & 13.889 & 26.625 & 84.940 & 575.546 & 14,8 \\
\hline 2003 & 53.334 & 21.608 & 31.047 & 105.989 & 690.206 & 15,4 \\
\hline 2004 & 48.230 & 20.003 & 35.909 & 104.142 & 739.658 & 14,1 \\
\hline 2005 & 41.948 & 23.733 & 40.835 & 106.516 & 786.257 & 13,5 \\
\hline 2006 & 43.852 & 33.341 & 48.684 & 125.877 & 911.568 & 13,8 \\
\hline 2007 & 32.341 & 35.773 & 35.493 & 93.607 & 688.851 & 13,6 \\
\hline
\end{tabular}

The evolution of the amount of completed housing finished each year can be observed in Table 2. The number increases until 2007, so showing the current time gap between economic and real estate cycles. The real estate cycle is enlarged one or two years over the economic cycle. These two years correspond to the amount of time necessary to finish the construction of housing started before the change in the economic cycle.

Table 2: Certificates of finished construction works: housing completed. Source: DG Promoción Económica, Ministerio de Fomento.

\begin{tabular}{|c|c|c|c|c|c|c|}
\hline Year & Alicante & Castellón & Valencia & C. Valenciana & Spain & \% CV / AND \\
\hline 2000 & 35.394 & 3.577 & 20.816 & 59.787 & 366.776 & 16,3 \\
\hline 2001 & 22.291 & 1.538 & 25.111 & 48.940 & 365.663 & 13,4 \\
\hline 2002 & 32.451 & 1.544 & 24.262 & 58.257 & 416.683 & 14 \\
\hline 2003 & 31.199 & 2.217 & 28.582 & 61.998 & 458.683 & 13,5 \\
\hline 2004 & 36.769 & 9.664 & 26.420 & 72.853 & 496.785 & 14,7 \\
\hline 2005 & - & - & - & 84.969 & 524.479 & 16,2 \\
\hline 2006 & - & - & - & 102.229 & 585.583 & 17,5 \\
\hline 2007 & - & - & - & 118.227 & 641.419 & 18,4 \\
\hline
\end{tabular}

Table 3 shows the evolution of housing both in Spain, and in the AC of Valencia. It is an estimation made by the Ministry of Housing of the Spanish Government. 
Table 3: $\quad$ Estimated amount of housing in Spain and in the AC of Valencia (1st January). Source: Ministerio de la Vivienda.

\begin{tabular}{|r|r|r|r|r|r|}
\hline & \multicolumn{1}{|l|}{ TOTAL SPAIN } & \multicolumn{1}{l|}{ Com Val } & \multicolumn{1}{l|}{ Alacant } & \multicolumn{1}{l}{ Castelló } & \multicolumn{1}{l}{ València } \\
\hline $\mathbf{2 0 0 1}$ & $\mathbf{2 1 . 0 3 3 . 7 5 9}$ & $\mathbf{2 . 5 5 8 . 6 9 1}$ & 1.009 .930 & 327.687 & 1.221 .074 \\
\hline $\mathbf{2 0 0 2}$ & $\mathbf{2 1 . 5 5 1 . 4 2 6}$ & $\mathbf{2 . 6 2 8 . 1 3 5}$ & 1.045 .016 & 337.557 & 1.245 .562 \\
\hline $\mathbf{2 0 0 3}$ & $\mathbf{2 2 . 0 5 9 . 2 2 0}$ & $\mathbf{2 . 6 9 2 . 3 8 9}$ & 1.078 .842 & 347.267 & 1.266 .280 \\
\hline $\mathbf{2 0 0 4}$ & $\mathbf{2 2 . 6 2 3 . 4 4 3}$ & $\mathbf{2 . 7 6 7 . 7 6 3}$ & 1.119 .274 & 358.920 & 1.289 .569 \\
\hline $\mathbf{2 0 0 5}$ & $\mathbf{2 3 . 2 1 0 . 3 1 7}$ & $\mathbf{2 . 8 6 2 . 6 5 8}$ & 1.164 .415 & 376.624 & 1.321 .619 \\
\hline $\mathbf{2 0 0 6}$ & $\mathbf{2 3 . 8 5 9 . 0 1 4}$ & $\mathbf{2 . 9 5 2 . 3 3 8}$ & 1.209 .266 & 391.998 & 1.351 .074 \\
\hline $\mathbf{2 0 0 7}$ & $\mathbf{2 4 . 4 9 5 . 8 4 4}$ & $\mathbf{3 . 0 3 7 . 5 8 9}$ & 1.243 .421 & 410.167 & 1.384 .001 \\
\hline
\end{tabular}

Table 4 shows the evolution of the population in Spain and in the ACV. If we compare these data with those in Table 3, we can verify that by 2007 there were 3.037.589 housing units and 4.885.29 inhabitants, that is 0,62 housing unit/inhabitant. That is not real at all, because many housing units are second residences, and in many cases for the EU non-Spanish population. This ratio is practically the same from 2002 (with an amount of 0,61) to 2007. In any case, the number of housing units is very high and the production of housing in this same period has also been very high.

Table 4: Official population data. Source: National Institute of Statistic, Local Census.

\begin{tabular}{|c|c|c|c|c|c|c|}
\hline $\begin{array}{c}\text { Year (1 } \\
\text { January) }\end{array}$ & Alicante & Castellón & Valencia & C. Valenciana & Spain & \% CV / AND \\
\hline 2002 & 1.557 .968 & 501.237 & 2.267 .503 & 4.326 .708 & 41.837 .894 & 10,3 \\
\hline 2003 & 1.632 .349 & 518.239 & 2.320 .297 & 4.470 .885 & 42.717 .064 & 10,5 \\
\hline 2004 & 1.657 .040 & 527.345 & 2.358 .919 & 4.543 .304 & 43.197 .684 & 10,5 \\
\hline 2005 & 1.732 .389 & 543.432 & 2.416 .628 & 4.692 .449 & 44.108 .530 & 10,6 \\
\hline 2006 & 1.783 .555 & 559.761 & 2.463 .592 & 4.806 .908 & 44.708 .964 & 10,8 \\
\hline 2007 & 1.825 .264 & 573.282 & 2.486 .483 & 4.885 .029 & 45.200 .737 & 10,8 \\
\hline
\end{tabular}

This shows a very intense process of land development. Obviously, these data reflect those development projects that have been really executed, but they do not include those others that have been designed, but that, for one reason or another, have never been implemented.

If we analyze the dates of CORINE land cover for: 1.1 urban fabric; 1.2 industrial, commercial and transports units; and 1.4 artificial non-agricultural vegetated areas, artificial surface for land cover increased between 1990 and 
2006. The increase between 2000 and 2006 is 1.770 ha per year and the increase between 1990 and 2000 was 1.794 per for year.

So, this shows a continuous land development process during this period. It is especially important to note that the average amount of land developed year by year during the so called "real estate boom" period of 2000-2006, is practically the same as that in the previous period of 1990-2000.

Table 5: Artificial surface (CORINE land cover 1.1, 1.2 and 1.4). Source: CORINE.

\begin{tabular}{rrrr}
\hline & $\mathbf{1 9 9 0}$ & $\mathbf{2 0 0 0}$ & $\mathbf{2 0 0 6 *}$ \\
\hline Urban fabric & 61.670 & 79.612 & 85.696 \\
$\begin{array}{r}\text { Industrial, commercial and } \\
\text { transport units }\end{array}$ & 10.696 & 18.897 & 22.988 \\
$\begin{array}{r}\text { Artificial non-agricultural } \\
\text { vegetated areas }\end{array}$ & 1.303 & 3.881 & 4.327 \\
Sum (ha) & $\mathbf{7 3 . 6 7 0}$ & $\mathbf{1 0 2 . 3 9 0}$ & $\mathbf{1 1 3 . 0 1 1}$ \\
\% surface areas ACV & 3,17 & 4,40 & 4,86 \\
\hline
\end{tabular}

*Estimated data for 2006 .

This group of data shows several facts. Land development during 2000 and 2006 has the same intensity as that in previous period, but it was of a very speculative character because housing prices had increased in a very important way.

The development of rural land into urban land remained almost constant from 1990 to 2007. It is known that there has been an abrupt stop in this process in 2008. Laws edited in the AC in 2004-2006 have the aim of establishing sustainability and life quality criteria in land development processes taking place during this time.

An important part of the implementation measures are linked to these development processes and produce expenses that are charged to the same process.

\section{Analysis of the implementation of legal reform}

\subsection{Main reform items}

Main items affected by legal reform are:

1. Territorial management in urban and regional planning:

a. Introduction Guidelines of Sustainability and Quality of Life in Urban and Regional Planning.

b. Sustainability payment if an excess of natural resources are consumed or for pollution emission.

c. Rule " 1 by 1 " for surrender to administration, when the local administration changes non-developable land to developable 
land, an equal amount of protected non-developable land should be surrendered.

2. Landscape regulation:

a. Application of the European Convention of Landscape, Florence 2000.

b. Introduction of Landscape Studies in Urban and Regional Planning

c. Introduction of a System of Big Spaces in the urban plan.

d. Introduction of a Landscape Catalogue in the urban plan.

e. Introduction of public participation for landscape valuation by a Public Participation Plan as a part of the urban plan.

3. Strategic Environmental Assessment (SEA)

a. Introduction of a system of public participation for environmental decision making.

b. Introduction of an Environmental Sustainability Report in Urban and Regional Planning.

\subsection{Experience for main reform items}

Experience has been very irregular up until now. Laws have introduced many new concepts and ideas, but in many cases the way in which they have been designed and developed has rarely been systematic or coherent.

Regulation has taken place through a very wide group of laws and norms that, many times, have incoherencies between them.

Sustainability and Life Quality Directives mainly have a character of general criteria.

The introduction of sustainability quotas is a good idea in order to punish the excess of consumption of natural resources and the emission of contaminants and to generate a fund in order to finance sustainability and quality of life projects.

However, a limit to the consumption of resources has only been established concerning land consumption. From 2006 on, Local Governments must pay a quota of $€ 6$ for each $\mathrm{m} 2$ of undevelopable land changed to developable land, when the amount of land so considered exceeds $15-20 \%$ of the developed land. However, for the moment, regional government does not demand the fulfilment of this condition.

In addition, this norm is very questionable because land portions of territory adequate for urban development are not equally distributed within the territory. So it is not natural to apply the same ratio in all municipalities.

On the other hand, during the real estate "boom" local governments made land development their main income source, because they obtained land from public endowments, an average of $10 \%$ of buildable land, public works already finished, and the economic incomes produced by building permits and activity permits, all of these linked to development processes.

The " 1 by 1" rule is being applied and has turned into an instrument for the public administration to obtain protected land.

Rules on landscape are more coherent, but professional tradition in landscape planning does not exist at all in either Spain or in the ACV. 
Land planning professionals do not usually have practice in landscape treatment and there are no guides or methodologies used in order to implement laws. In addition, it is necessary to integrate landscape architecture in environmental planning [3].

Landscape protection, management and planning are essential to keep a tourist activity of quality in the ACV. Tourism is an important economic sector in the ACV due, among other things, to the quality of the Mediterranean landscapes. An excess of developed land produces an overcrowded urbanization that rapidly introduces urban, economic and social degradation processes. This degraded landscape lacks interest to visitors. This is the reason why retaining the quality of the territorial and urban landscape produced is essential for the economic sector.

The Aarhus Convention and the SEA have been implemented through Central Government laws in 2006, complemented with the Land Act of 2007. The new proceedings and documents that these laws require for the urban plan are not foreseen in ACV legislation. All of these matters generate a situation of juridical insecurity in the fulfilment of laws due to the fact that they show contradictory situations.

There is no experience of public participation processes oriented to decision taking. The society is not accustomed to these processes. There is experience of public participation with a complaining character, but not for decision-taking. On the other hand, in general, politic organizations are rarely favourable to participation processes that could condition their decisions.

There is neither an established methodological scheme, nor a development of the contents of the documents foreseen in the SEA. This shows that, despite everything, there is a great lack of contents and essential doubts in the implementation of the laws.

The Environmental Impact Assessment (EIA) and Strategic Environmental Assessment (SEA) have a special methodological relation [4].

Paradoxically, urban plans in the ACV have been subject to environmental impact evaluation since 1999. As such, there is a great deal of experience in this matter with a type of environmental impact evaluation that, in fact, is a kind of SEA. Nevertheless, a parallel process is taking place so the two processes concerned are completely different. This means that urban plans are subject to environmental impact evaluation and to SEA, but, in fact, there is great confusion on the implementation of these different instruments, though both have very similar objectives.

The first plan promoted by the ACV as completely fulfilling landscape norms and SEA proceedings is the "Plan d'Acció Territorial de Protecció de L'Horta de València". The preliminary version of this plan was shown to the public through a very intense process of public participation that took place from June to December 2008. It can be consulted on the website of the AC Government [5]. If this plan and proceeding is successful, it could be turned into an example for future cases.

In Spain there are penal punitions against land planning and environmental matters. It was two years ago that the Environmental Central Attorney was 
created by central government. This permits more rigorous processes in the prosecution of environmental and urban crimes, and it strives for greater guarantees for the fulfilment of environmental rights.

\section{Fundamental problems}

Despite all of these legal changes, a complete set of essential problems already exist that have not yet been approached.

Firstly, we should mention the temporality of administrative protection on land environmental values. It is quite frequent that protected land is unprotected in order to establish urban uses of any kind. There is no system to guarantee the maintenance of recognized environmental values in the long term.

Secondly, we should also mention the dependence of environmental organisms on governments. This has as a consequence that, sometimes, environmental informs included in environmental impact evaluations or in the environmental memories of the SEA are not independent or objective at all.

There does not either exist a consideration of the value of the environmental services generated by spaces with environmental values. This is the reason why landowners do not want their land to be protected, because this situation generates conditions and limits uses with little compensation for protection.

Due to the continuous changes in norms, there is no complimenting juridical security. It is very difficult to plan cities and territories in a context in which norms are changing in a very quickly, with not even enough time for the laws and their correct implementation to become well known.

Society generates an ecological footprint, or even better, an ecological larder. European societies import environmental services generated by the ecological pantry existing on territories mainly located outside Europe. It is necessary to guarantee the maintenance of the ecological larder in the long term, and in our own territory.

\section{Conclusion}

At the moments there are a great amount of laws in the ACV that regulate environmental and landscape matters, all of which are included in urban and regional planning.

These laws have the aim of developing very valuable ideas and objectives to form sustainability and quality of life points of view. However, the way in which ideas are implemented is not very systematic, and even incoherent. This is the reason that the implementation of laws is difficult, making them inefficient.

At the same time, an important part of the essential problem, the resolution of which is necessary to resolve sustainability in urban development, has not yet been approached.

In particular, we appreciate the necessary creation of new structures independent from public powers in order to guarantee the maintenance of environmental values and services given by the territories that by now have the character of ecological larders. 
It is necessary for laws to be systematic, rigorous, and operative in order to be efficient on the acquirement of their objectives.

\section{References}

[1] Miralles i Garcia, J.L. The introduction of the sustainability in the procedures regulated for urban planning: the case of the last act on urbanism, territory and landscape in the Valencian Community (Spain). Proc of the $3^{\text {rd }}$ Int. Conf. on Sustainable Development and Planning, eds. A. Kungolos, C.A. Brebbia \& E. Beriatos, WIT Press: Southampton, pp. 505513, 2007.

[2] Miralles i Garcia, J.L. Landscape management. Case study: the situation in the Autonomous Community of Valencia (Spain). Proc of the $1^{\text {st }}$ WSEAS International Conference on Landscape Architecture, eds, T. Panaopoulos \& J.B. Burley, WSEAS Press: Algarve, pp. 17-22, 2008.

[3] Chenoweth, A. Integrating landscape architecture in environmental planning for sustainable growth management. Proc of the $1^{\text {st }}$ WSEAS Int. Conf. on Landscape Architecture, eds, T. Panaopoulos \& J.B. Burley, WSEAS Press: Algarve, pp. 44-52, 2008.

[4] Cole, P. \& Broderick, M. Environmental Impact Assessment (EIA) and Strategic Environmental Assessment (SEA): an exploration of synergies through development of a Strategic Environmental Framework (SEF). Proc of the $3^{\text {rd }}$ Int. Conf. on Sustainable Development and Planning, eds. A. Kungolos, C.A. Brebbia \& E. Beriatos, WIT Press: Southampton, pp. 313$321,2007$.

[5] GENERALITAT VALENCIANA. http://www.gva.es/ in Environment, Water, Town Planning and House Department. 